\title{
Early Jurassic allotherians from South Wales (United Kingdom)
}

\author{
William A. Clemens* \\ Museum of Paleontology, 1101 Valley Life Sciences Building, University of California, Berkeley, California 94720-4780, U.S.A.
}

Received 7 June 2006, accepted 5 July 2006

Published online 30 January 2007

With 6 figures and 1 table

Key words: Thomasia, Allotheria, Haramiyidae, Mammalia, Taxonomy, Early Jurassic, South Wales.

\begin{abstract}
Fossils from two fissure fillings in Pant Quarry (designated Pant 4 and Pant 5), South Wales, United Kingdom, probably of Early Jurassic age document a taxonomically diverse vertebrate fauna, the Morganucodon-sphenodont fauna, composed of several kinds of reptiles, non-mammalian synapsids, and mammals. Six isolated molariform teeth from Pant 4 and 5 fissures clearly record the presence of Thomasia (Mammalia, Allotheria, Haramiyidae), a genus previously known only from purported Late Triassic faunas of southwestern England, France, Belgium, Luxemburg, Germany, and Switzerland. Small morphological differences from teeth in the larger English and continental European samples warrant identification of the Welsh material as Thomasia cf. moorei. The highly derived morphology of an isolated molariform tooth from Pant 5 fissure indicates the presence of another, possibly allotherian, taxon.
\end{abstract}

Schlüsselwörter: Thomasia, Allotheria, Haramiyidae, Mammalia, Taxonomie, Unterer Jura, Süd-Wales.

\section{Zusammenfassung}

Fossilien aus zwei wahrscheinlich unterjurassischen Spaltenfüllungen (Pant 4 und Pant 5) im Steinbruch Pant in Süd-Wales dokumentieren eine taxonomisch diverse Wirbeltierfauna. Diese Morganucodon-Sphenodontiden-Fauna besteht aus verschiedenen Formen von Reptilien, Synapsiden und Säugetieren. Sechs isolierte molariforme Zähne aus den Spaltenfüllungen Pant 4 und Pant 5 belegen eindeutig das Vorkommen von Thomasia (Mammalia, Allotheria, Haramiyidae), einer bisher nur aus vermutlich obertriassischen Faunen Südwest-Englands, Frankreichs, Belgiens, Luxemburgs, Deutschlands und der Schweiz bekannten Gattung. Geringe morphologische Unterschiede zu dem umfangreicheren Material aus England und KontinentalEuropa sprechen für die Identifikation des neuen Materials als Thomasia cf. moorei. Die stark abgeleitete Morphologie eines isolierten molariformen Zahnes aus der Spalte Pant 5 belegt das Vorkommen eines anderen Taxons, das möglicherweise auch den Allotheria zuzuordnen ist.

\section{Introduction}

Currently available fossil records of Late Triassic and Early Jurassic terrestrial faunas document the diversification of advanced non-mammalian synapsid and early mammalian (sensu Luo 1994; or mammaliaform, sensu Rowe \& Gauthier 1992) lineages. A significant part of this record is derived from deposits in continental Europe and southwes- tern United Kingdom (see Kielan-Jaworowska et al. 2004). During the transition from the Triassic into the Jurassic southern Wales and southwestern England were gradually flooded by the transgressing Tethyian Sea. A karst topography developed on highlands formed by gently folded Carboniferous limestones that are now partially exposed in the Vale of Glamorgan, South Wales, and Bristol-Mendip region of southwestern England (Fig. 1). As

\footnotetext{
*E-mail: bclemens@berkeley.edu
} 


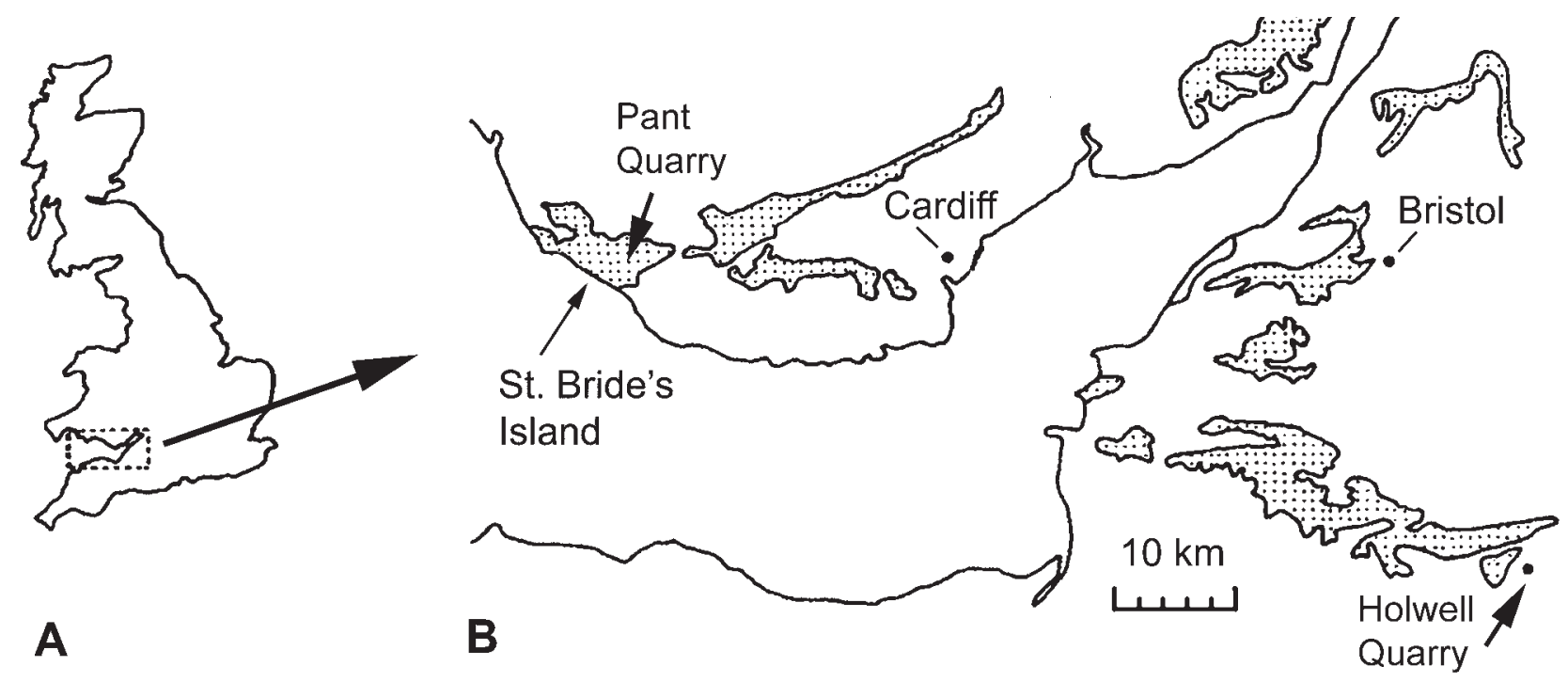

Fig. 1. A - Map showing location of the Bristol Channel area in Britain; B - Bristol Channel area with locations of Pant Quarry and Holwell Quarry designated, major outcrops of Carboniferous limestones shown in coarse stipple, redrawn from Evans and Kermack (1994), based on British Geological Survey Sheet, 1979.

this sea advanced highlands became isolated as islands before being fully inundated in the Early Jurassic - Sinemurian (bucklandi zone (Evans \& Kermack 1994)). Late Triassic and Early Jurassic sediments deposited in fissures and caves within the Carboniferous limestones preserve remarkable samples of the terrestrial vertebrate faunas of the dwindling archipelago. For further information on the geology of the area see Evans \& Kermack (1994), Gill (2004), Benton \& Spencer (1995), Benton et al. (2005), and references cited in these publications.

Pant and several other commercial quarries are situated in the western part of the Welsh outcrops of Carboniferous limestones (Fig. 1). At the beginning of the Early Jurassic this area is thought to have been a single island, named St. Bride's Island by Robinson (1957). Building on discoveries made by Prof. Walter Kühne in the early 1950s, Prof. Kenneth A. Kermack and his teams from University College London began collecting and processing fossiliferous sediments from fissure fillings exposed in quarries in the St. Bride's Island area. The Welsh material analyzed here came from two fissure fillings exposed in Pant Quarry, designated Pant 4 and 5 (Fig. 1, see Kermack et al. 1973; Gill 2004; Säilä 2005a for detailed locality data). Evans \& Kermack (1994) and Gill (2004) reviewed the history of collecting and research on the Pant Quarry faunas. In recent years Dr. Pamela Gill and associates at the University of Bristol have continued to study the Early Jurassic faunas of southern Wales (Gill 2004; Säilä 2005a).

The early collections made by Prof. Kermack and his teams from Pant and adjacent quarries within the St. Bride's Island area sampled a biota that was dubbed the Hirmeriella association after a conifer commonly preserved in these fissure fillings (Ker- mack et al. 1973). The common vertebrates in this association are a lepidosaur, Gephyrosaurus bridensis Evans, 1980, and a mammal, Morganucodon watsoni Kühne, 1949. Another consistent but rarer member of the association is the mammal Kuehneotherium praecursoris Kermack, Kermack \& Mussett, 1968. Research on these collections has already produced detailed reconstructions and analyses of some of its reptilian (e.g., Evans 1980, 1981) and mammalian (e.g., Kermack et al. 1973, 1981; Gill 2004) members.

The typical Hirmeriella association is just one aspect of the faunal diversity preserved in the Welsh fissures. In 1968 commercial quarrying began to expose a new fissure at Pant Quarry, designated Pant 4 by Prof. Kermack (Evans \& Kermack 1994). This fissure filling contained specimens of Hirmeriella and the three characteristic vertebrate taxa of the Hirmeriella association. It also yielded remains of several additional kinds of reptiles, non-mammalian synapsids, and mammals. Among the latter was the first record of a haramiyid from South Wales. A systematic analysis of the collection from Pant 4 was the subject of Dr. David Pacey's dissertation research (Pacey 1978). Unfortunately the very significant results of his study were never published.

In 1979 continuing excavation at Pant Quarry exposed yet another fossiliferous fissure filling, designated Pant 5, and some of the fissure filling was processed by Prof. Kermack's team. Subsequently Dr. Pamela Gill and students at the University of Bristol continued to process sediments from Pant 4 and Pant 5 collected under the direction of Prof. Kermack. Among the vertebrate fossils recovered by the Bristol group is a second haramiyid molariform found in sediments collected from Pant 4 fissure in 1978. Three well preserved haramiyid molariforms and some other isolated allotherian teeth 
were discovered in sediments collected from Pant 5 fissure in 1979. As now known the fauna from Pant 5 resembles that recovered from Pant 4 in its relatively high taxonomic diversity. This and several other studies (e.g., Gill 2004; Säilä 2005a, 2005b) build upon Dr. Pacey's (1978) dissertation research and take advantage of these new collections.

\section{Materials and methods}

In her recent study of samples of Kuehneotherium from various quarries in the St. Bride's Island area Gill (2004) suggested that the fauna of the Hirmeriella association with low taxonomic diversity be designated the Morganucodon fauna and the vertebrate fauna of higher taxonomic diversity, sampled in Pant 4 and Pant 5 fissures, be designated the Morganucodon-sphenodont fauna. This practical differentiation is adopted here.

Prior to its discovery in Wales Thomasia was known from bone beds and fissure fillings in southwestern England (Holwell Quarry), France, Belgium, Luxemburg, Germany, and Switzerland. Currently these occurrences of Thomasia are thought to be of latest Triassic (Rhaetian) age. The age of the Morganucodon-sphenodont fauna currently is thought to be Early Jurassic, most likely early Sinemurian (see Evans \& Kermack 1994; Kielan-Jaworowska et al. 2004). The bases for these age determinations are not conclusive. Gill (2004) argued that the Morganucodon fauna might be younger than the Morganucodon-sphenodont fauna with the loss of taxonomic diversity possibly reflecting the decreasing area of St. Bride's Island leading up to its inundation. Also she (Gill 2004) questioned the assignment of an Early Jurassic age to these faunas. For the purposes of this report the Morganucodon-sphenodont and possibly younger Morganucodon fauna are provisionally treated as Early Jurassic in age recognizing that these age assignments are open to modification on the basis of future research.

Knowledge of the morphology of the haramiyid dentition was greatly advanced by Sigogneau-Russell's (1989) study of a large sample of isolated teeth (over 200 specimens) from a Rhaetian deposit in France. Building on her study as well as an analysis by Hahn (1973), Butler \& MacIntyre (1994) added support for Sigogneau-Russell's (1989) working hypothesis that Thomasia and Haramiya, the junior synonym, were based, respectively, on the lower and upper molariforms of the same taxon. In this and subsequent studies (Butler 2000; Butler \& Hooker 2005) a series of hypotheses was advanced concerning the orientation and mode of occlusion of the molariform teeth of Thomasia. The following are pertinent to this study:

On upper molariforms of Thomasia - the "Haramiya type" of molariform - the A row of cusps, Parrington's (1947) "row of 3", is characterized by cusp A1 being lower than cusp B1 of the B row and A1 is either smaller than or equal to A2 and A3 (Fig. 2).

The end of the crown of an upper molariform bearing the highest cusp in the B row, the so-called $(+)$ end of the

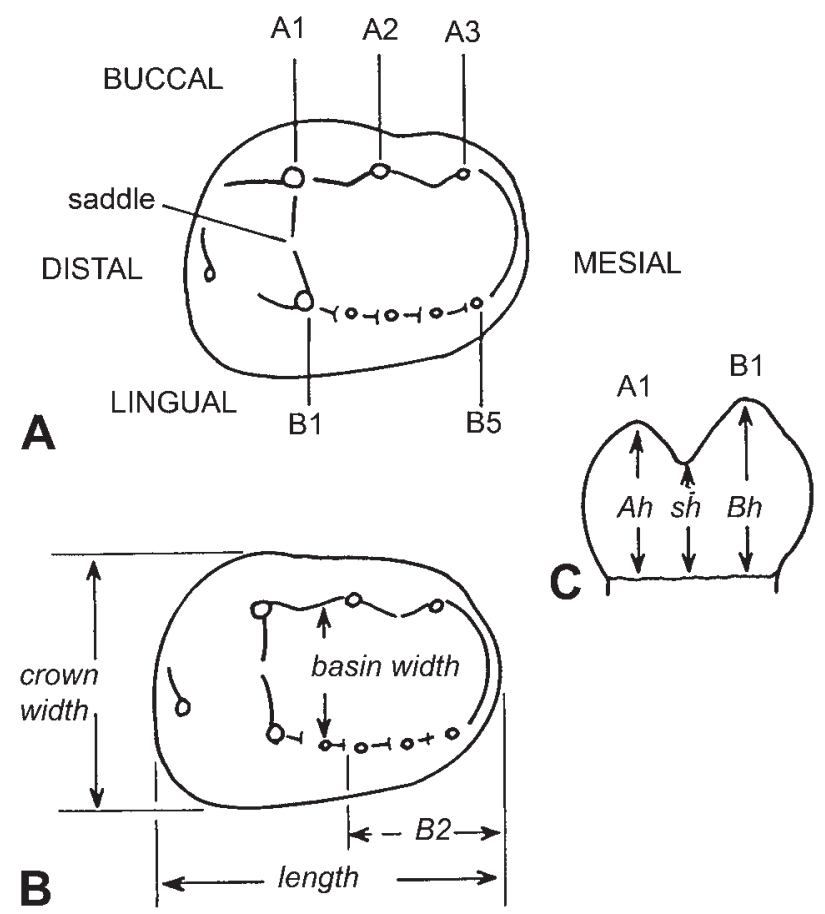

Fig. 2. Outline drawings of a generalize haramiyid upper molariform (redrawn from Butler \& MacIntyre 1994). A - Occlusal view; A1, A2, A3 - cusps of the buccal (labial), A row; B1, B5 - cusps of the lingual, B row; B - occlusal view illustrating measurements reported in Table 1; B2 - distance between the groove separating cusps B2 and B3 and the mesial end of the crown; $\mathbf{C}-$ cross section of crown at level of A1 and B1 illustrating measurements reported in Table 1; A1, B1 - heights of the apices of cusps A1 and B1 above the base of the enamel; sh - height of notch in the saddle above the base of the enamel.

crown (Butler \& MacIntyre 1994), is assumed to be its distal end.

On upper molars the A row of cusps is assumed to be buccal (labial) and the B row lingual.

Measurements (Table 1), in millimeters, were taken according to the scheme advocated by Butler \& MacIntyre (1994) and illustrated in Fig. 2.

In order to obtain scanning electron microscope images molds were made of the teeth with Coltène President $\mathbb{R}$, light body (Coltène/Whaledent Inc., 750 Corporate Drive, Mahwah, New Jersey, 07430, USA) and then reinforced with Dow Corning 732, multi-purpose, silicone sealant. Arolite Epoxy resin casts made from these molds were coated with gold-palladium and images obtained in an Hitachi S-2500 microscope. The resulting images were retouched to remove traces of dust particles and produce an uniform background.

Institutional abbreviations. Vertebrate fossils in the first collections from Pant 4 fissure, informally referred to as the "Pacey fissure", initially were recorded in the University College London Zoology Department catalogue with num-

Table 1

Dimensions of molariforms of Thomasia cf. moorei (Owen, 1871) in millimeters. See Fig. 2 for explanations of measurements.

\begin{tabular}{|c|c|c|c|c|c|c|c|}
\hline \multirow{2}{*}{$\begin{array}{l}\text { Specimen } \\
\text { Number }\end{array}$} & \multicolumn{3}{|l|}{ Crown } & \multirow{2}{*}{$\begin{array}{l}\text { Basin } \\
\text { Width }\end{array}$} & \multicolumn{3}{|c|}{ Heights } \\
\hline & Length & Width & B2 & & A1 & Saddle & B1 \\
\hline M45420 & & 1.40 & & 0.92 & & & \\
\hline M45421 & 2.43 & 1.93 & 1.21 & 1.07 & ca 0.9 & ca 0.5 & ca 1.1 \\
\hline M45422 & 2.93 & 2.11 & 1.54 & 1.00 & & ca 0.6 & \\
\hline M63693 & & 2.00 & & 0.80 & & & \\
\hline
\end{tabular}


bers carrying the prefix "U". They and the other fossils from Pant 4 and 5 fissures described and analyzed here have been catalogued in the collections of the Department of Palaeontology, The Natural History Museum, London, United Kingdom, and now have specimen numbers with the prefix " $M$ ", e.g., M45425. Reference is made to a fossil in the collections of the Museum of Comparative Zoology, Harvard University, Cambridge, USA, which has a specimen number with the prefix "MCZ".

\section{Systematic Paleontology}

Subclass Allotheria Marsh, 1880

Order "Haramiyida" Hahn, Sigogneau-Russell \& Wouters, 1989

Suborder Haramiyoidea Hahn, 1973

Family Haramiyidae Simpson, 1947

Dis cussion. Butler (2000) revised allotherian systematics recognizing two ordinal groups, the probably paraphyletic "Haramiyida" and the Multituberculata. Of these multituberculates are by far the longest ranging and best represented in the available fossil record (see Kielan Jaworowska et al. 2004). Their oldest, incontrovertible record is of Middle Jurassic age (Butler \& Hooker 2005); the last appearance of the group is of Late Eocene age. Haramiyidae is one of four currently recognized "haramiyidan" families (Kielan-Jaworowska et al. 2004). On the Laurasian continents occurrences of haramiyids range from the Late Triassic into the Early Jurassic. All are referred to the genus Thomasia and known only from isolated teeth. One Gondwanan haramiyid, Allostaffia, from the Late Jurassic of Africa, has been described so far (see Heinrich 1999, 2001, 2004). A possible record of a "haramiyidan" has been discovered in Late Cretaceous strata in India (Anantharaman et al. 2006).

\section{Thomasia Poche, 1908}

\section{Thomasia cf. moorei (Owen, 1871)}

Figs 3, 4, 5

Referred material. Synonyms used in field and museum records are listed in parentheses: Pant 4 fissure: M45420 (=U 568, "Pacey's specimen"), fragmentary molariform assumed to be a right upper; and M63693 (="2003 specimen"), right upper molariform. Pant 5 fissure: M45421 (= Specimen A), left upper molariform; M45422 (= Specimen B), left upper molariform; M45423 (= Specimen C), fragment of a molariform with two cusps, central basin, and one complete root; M45426 (= Specimen F), fragment of a molariform: M45424 (= Specimen D), upper incisiform.

Description. Molariforms - M45421, left upper molariform from Pant 5 , has an essentially complete crown (Fig. 3A, B, C, D). Cusp A1 is distinctly lower than B1. A V-shaped central basin separates these cusps. Worn bases of narrow, low, vertical ridges on the directly opposing faces of $\mathrm{A} 1$ and $\mathrm{B} 1$ meet to form the notch in the relatively low saddle. On the distal end of the crown a narrow, short basal cingulum extends from the base of $\mathrm{A} 1$ onto the base of B1. A2 is slightly higher than A1 and about the same height as B2. The internal slope of A2 is distinctly larger than that of A1 resulting in deflection of the floor of the central basin toward the $\mathrm{B}$ row. A3 is more widely separated from A2 than A2 is from A1. A sharp crest on the mesial side of $\mathrm{A} 2$ swings around the buccal base of $\mathrm{A} 3$ producing

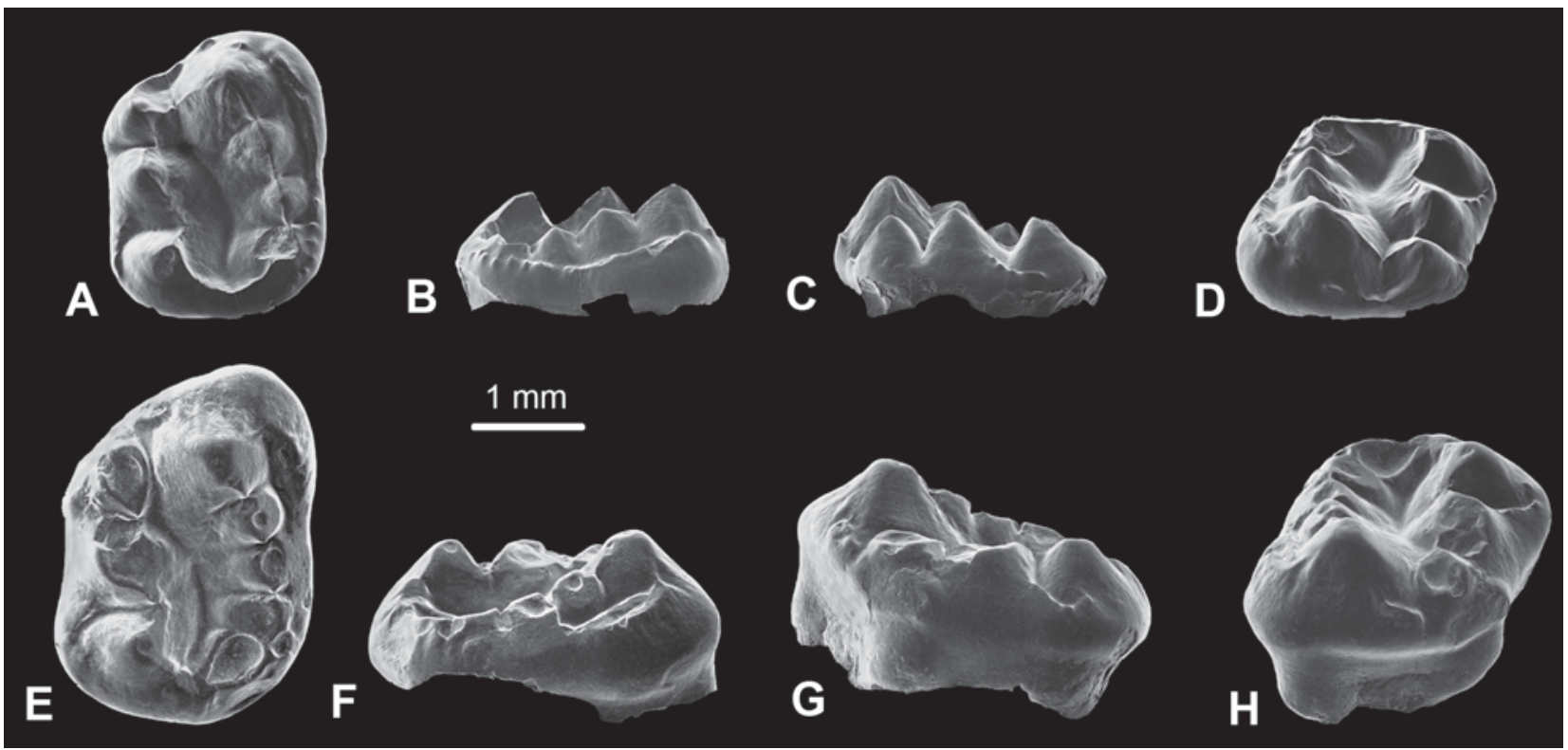

Fig. 3. Upper left molariforms of Thomasia cf. moorei (Owen, 1871). M45421. A - Occlusal view, distal toward top, lingual to right; B - lingual view, distal to right; $\mathbf{C}$ - buccal view, distal to left; $\mathbf{D}$ - oblique view, distal in foreground, buccal to right. M45422; E - occlusal view, distal toward top, lingual to right; $\mathbf{F}$ - lingual view, distal to right; $\mathbf{G}$ - buccal view, distal to left; $\mathbf{H}$ - oblique view, distal in foreground, buccal to right. 
a short, narrow cingulum. The deepest part of the central basin is near the mesial end of the crown opposite A3.

$\mathrm{B} 1$ is the highest cusp of the crown. B2 and B3 are relatively smaller and sequentially lower cusps. The apex of B4 is broken away. The "U-shaped" ridge linking $\mathrm{B} 4$ and $\mathrm{A} 3$ forms the steep wall of the mesial end of the central basin. A distinct cingulum lingual to the $\mathrm{B}$ row extends from the lingual side of B1 to the lingual side of B3. A narrow shelf separates its papillate margin from the sides of B1 through B3. Two small cusps at about the level of this cingulum are present on the distal side of B1. Similarly several minute cusps extend the course of the cingulum toward the mesial end of the crown. The roots of the tooth are not preserved.

M45422, left upper molariform from Pant 5 (Fig. 3E, F, G, H), is larger than M45421 (Table 1). The apex of A1 is missing but it appears to have been smaller than B1. Resembling M45421 these cusps are separated by a V-shaped valley ending in a narrow cleft and linked by a relatively low saddle. There is no indication of vertical ridges on the opposing faces these cusps. On M45422 a short basal cingulum on the disto-buccal slope of B1 ends above the notch in the saddle. A small vertical facet on the buccal and distal sides of A1 of M45422 might be an interdental wear facet. The apex of A2 also is missing, possibly the result of a combination of wear and breakage. Cusps A2 and A 3 as well as the central basin are morphologically similar to those of M45421.

B1 is the highest cusp on the crown. B2 to B4 are relatively small, sequentially lower cusps mesial to B1. All four show some apical wear. Mesial to B4 a circular gap in the enamel opens into a deep pit in the dentine. This might mark the position of a fifth cusp in the B row. Lingual to the distal end of the $\mathrm{B}$ row the crown is not as bulbous as that of M45421. The lingual basal cingulum of M45422 is narrower, extends only along the sides of B1 and

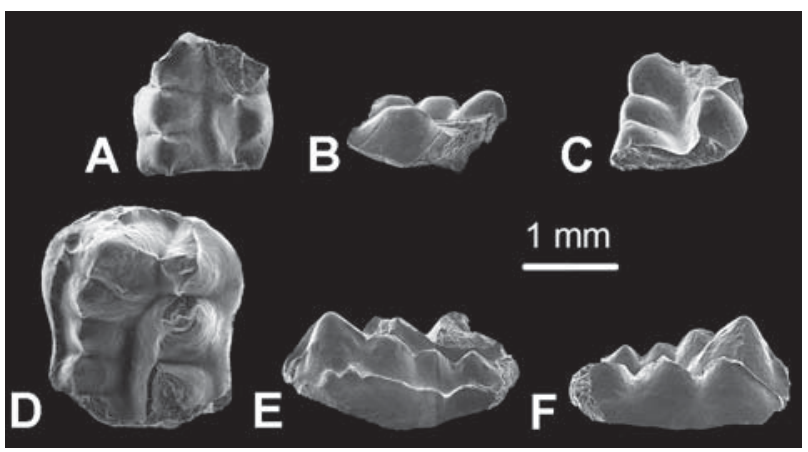

Fig. 4. Thomasia cf. moorei (Owen, 1871). M45420, assumed to be a right, upper molariform. $\mathbf{A}$ - occlusal view, distal toward top, lingual to left; B - buccal view, distal to right; C - oblique view, mesial in foreground, buccal to right. M63693, right upper molariform; D - occlusal view, distal toward top, lingual to left; $\mathbf{E}$ - lingual view, distal to left; $\mathbf{F}$ - buccal view, distal to right.
B2 to end at B3. Minute basal cusps extending the course of the cingulum mesially are not developed.

What appears to be an interdentinal wear facet is present at the mesial end of the B row. Fragments of the bases of the two roots are preserved. The posterior root is as broad as the crown and on its distal face there is a slight medial indentation. Most of the root that supported the anterior end of the crown is missing.

M45420 is the fragment of a molariform from Pant 4 discovered by Dr. David Pacey (Fig. 4A, B, C). It lacks both the mesial and distal ends of the crown and two of the five remaining cusps are damaged. Because of lack of evidence concerning the relative heights of cusps $\mathrm{A} 1$ and $\mathrm{B} 1$ whether M45420 is a fragment of an upper or lower molariform cannot be determined. The narrow width of its crown relative to those of the other molariforms from Pant 4 and 5 fissures suggests but does not definitively indicate it might be a lower molariform (Butler \& MacIntyre 1994). For sake of convenience in description it will be assumed to be an upper molariform. On M45421 and M45422 the central basin increases in depth mesially. The deepest end of the central basin of M45420 is assumed to be mesial. If these assumptions are correct M45420 is a fragment of an upper right molariform.

Only one cusp of the A row - probably A2 - is fully preserved. This cusp is somewhat elongated mesiodistally and blunted by apical wear. Only part of the base of the mesial side of A1 remains. The course of the central basin is slightly sinuous. It gradually deepens as it swings around the base of A1 and is deflected again around the mesial side of A2, where it reaches its maximum depth.

Only the apex of B1 and a large part of its internal side are preserved so the presence of a basal cingulum or cusps on the lingual margin of the crown cannot be determined. A very short vertical ridge on its internal side probably ended in the central basin. The apices of the well separated B1, B2 and B3 cusps are blunted by apical wear. A distinct crest, most strongly developed in the transverse valleys separating these cusps, links their apices. On the mesial side of B3 this crest is deflected internally and the surface of the crown rises suggesting the presence of a B4 cusp placed slightly more internally than $\mathrm{B} 3$, which is characteristic of most haramiyid molariforms.

M63693 is a fragment of a right upper molariform from Pant 4 (Fig. 4D, E, F). The three cusps of the A row are of approximately the same height and their apices are blunted. The central basin is deflected around the base of A2 and is deepest opposite the mesial half of $\mathrm{A} 2$ and $\mathrm{A} 3$. The remnant of what might have been a small distal basal cusp is present on B1, the largest and highest cusp of the crown. Crests extend from the apices of A1 and $\mathrm{B} 1$ to enclose a small depression distal to the 


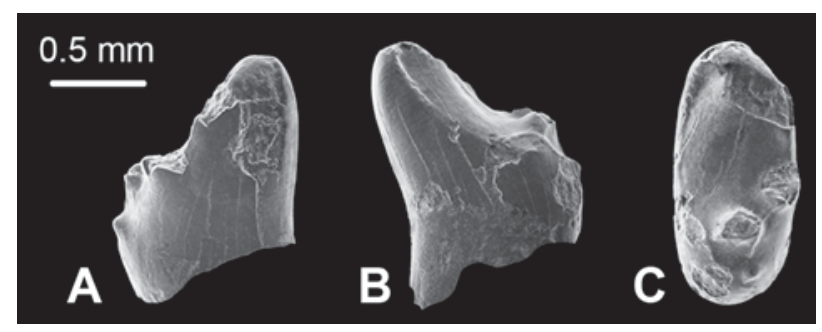

Fig. 5. ?Thomasia cf. moorei (Owen, 1871). M45424, assumed to be a left, upper incisiform. A - Assumed buccal view, mesial to right; B - assumed lingual view, mesial to left; C - mesial toward top, assumed buccal side to right.

relatively low saddle. B2, B3, and B4 are successively lower cusps. The apices of all the B cusps are linked a sharp ridge. A nearly continuous cingulum, lacking distinct cusps but interrupted by a few irregular gaps, extends along the lingual side of the crown.

M45423, fragment of a molariform tooth from Pant 5, is of appropriate size and morphology to be referred to Thomasia cf. moorei. What remains of the crown can be interpreted as including A2 and A3 and the mesial end of the central basin. The specimen is of interest because of the preservation of its nearly complete mesial root, which is approximately as broad as the crown and mesodistally narrow. The root is demarked from the crown by a distinct groove. Traced away from the crown the vertical depressions in the mesial and distal faces of the root become deeper and near its base the root is divided into two discrete units. Dimensions of the root are: dorsoventral length, $2.4 \mathrm{~mm}$; anteroposterior width (at mid-length), $1.0 \mathrm{~mm}$; lateral width (at mid-length), $1.5 \mathrm{~mm}$.

Incisiform - M45424, an incisiform tooth from Pant 5 , is supported by a single, transversely flattened root with a minimum length of $1.7 \mathrm{~mm}$ (Fig. 5A, B, C). Probably through a combination of wear and breakage the enamel is missing from the apex and what is assumed as the mesiobuccal face of its crown. Its distal face is asymmetrical with a cingulum-like depression along its assumed lingual side. Three cusps are present at the distal end of the concave (when viewed laterally) occlusal surface of the crown. A fourth cusp lies above them in the middle of the distal face of the crown. In general morphology M45424 resembles isolated teeth that have been tentatively identified as upper second incisors of haramiyids. Dimensions of the crown (following the system developed by Sigogneau-Russell 1989) are: minimum height, $1.3 \mathrm{~mm}$; mesiodistal length, $1.0 \mathrm{~mm}$; width, $0.7 \mathrm{~mm}$.

Discussion. Butler \& MacIntyre (1994) published the most recent revision of the species of the Haramiyidae in which size was a primary criterion. They recognized Thomasia moorei as the appropriate name for the larger species of hara- miyid in the collections from Holwell Quarry, Somerset, England; Saint-Nicolas-de-Port, France (Sigogneau-Russell 1989); and Hallau, Switzerland (Clemens 1980). Of the six complete and fragmentary haramiyid molariforms from Pant 4 and 5 fissures only three (M45421, M45422, M63693) preserve the characters necessary to definitely determine whether they are upper or lower molariforms. All appear to have been upper molariforms. Intriguingly a preponderance of upper molariforms also characterizes the sample of T. moorei from Holwell Quarry (Butler \& MacIntyre 1994).

The maximum widths of four molariforms from Pant 4 and 5 can be measured, but because of breakage the maximum lengths of only the two from Pant 5 can be determined (Table 1). As noted above the narrow width of M45420 in comparison to the other three suggests it might be a fragment of a lower molariform. The relative height of the first cusps of its A and B rows, which provides the character clearly distinguishing upper and lower molariforms, cannot be determined.

The lengths and widths of M45421 and M45422 and the width of M63693, all upper molariforms, could be measured (Table 1). In these dimensions of the crown the three specimens either fall at the high end or slightly above the ranges of variation reported by Butler \& MacIntyre (1994) for the sample of Thomasia moorei from Holwell Quarry. Other distinguishing characters of the upper molariforms of T. moorei cited by Butler \& MacIntyre (1994) included the presence of five cusps in the $B$ row, although they noted that in one referred specimen from Hallau only four B cusps were present. Either four or possibly five B cusps are present in the molariforms from Pant. Finally they noted that the $B 2$ dimension (see Fig. 2) was $45-50 \%$ of crown length. On the two molariforms from Pant 5 on which these dimensions could be measured this ratio is $50 \%$ and $72 \%$.

The molariforms from Pant 4 and 5 clearly differ from those of Thomasia moorei from Holwell in the relatively greater development of a cingulum on the distolingual slopes of row B. Butler \& MacIntyre (1994) note the presence of indistinct cingular development on the lingual slopes of Holwell Quarry specimens H 211 and H 213. The development of cingula on the distolingual slopes of M45422 and especially M452421 and M63693 is much stronger.

Butler \& MacIntyre (1994, p. 448) referred only one fragmentary incisiform from Holwell Quarry (H 14, in the collections of the Museum of Zoology, Cambridge University) to Thomasia moorei noting, "... it closely resembles teeth identified as I2/ by Sigogneau-Russell (1989)." Although broadly resembling H 14, the crown of M45424 is somewhat smaller and differs in having a less salient apex. Similarly, although differing in morphological details, 
M45424 also resembles isolated teeth from SaintNicolas-de-Port tentatively identified as upper second incisors of haramiyids by Sigogneau-Russell (1989, e.g. see figs 54, 56).

In summary, the isolated haramiyid teeth from Pant 4 and 5 fissures clearly establish the presence of this group in the Morganucodon-sphenodont fauna of the Early Jurassic of Wales. Similarities in size and morphology revealed in comparisons with the larger samples of teeth of Thomasia from Holwell Quarry and Saint-Nicolas-de-Port show that the Pant 4 and 5 haramiyid is referable to this genus. As well as extending the geographic range of Thomasia into Wales, they might document the survival of the genus across the Triassic-Jurassic boundary.

Referring to the classification of the species of Thomasia established by Butler \& MacIntyre (1994) and assuming that the Welsh teeth represent but one species, the closest comparisons are with T. moorei known from Holwell Quarry, Saint-Nicolas-de-Port, and Hallau. There are differences however. If substantiated by larger samples from Pant, the somewhat larger sizes of the crowns of the upper molariforms and the greater development of cingula and small cusps on the distal and lingual slopes of cusps in row B might warrant recognition of a new species. Given the small sizes of the available samples from the Pant 4 and 5 fissures, for the moment the best course of action is to identify these specimens as Thomasia cf. moorei and await discovery of more material.

?Subclass Allotheria Marsh, 1880

Fig. 6

Referred material. Pant 5 fissure: M45425, a poorly preserved, molariform tooth.

Description. M45425 is a minute, poorly preserved tooth (Fig. 6A, B, C, D) that appears to document a hitherto unknown member of the Morganucodon-sphenodont fauna. In the context of currently known Late Triassic and Early Jurassic synapsids comparisons have been made with the postcanine dentitions of allotheres ("haramiyidans" and multituberculates), diademodontoids, and tritylodontids, which show some morphological similarities. These comparisons suggest that for the purposes of describing its morphology the following working assumptions can be made concerning orientation of the crown of M45425. The two parallel rows of cusps and the deep, continuous central basin are assumed to have been oriented mesiodistally. In the groups used in the comparisons the lower molariforms are narrower transversely than the uppers. The narrowness of the crown of M45425 (length/width ratio $=1.78$ ) is suggestive of a lower molariform. In lineages of advanced nonmammalian synapsids and primitive mammals, including the allotheres, movement of the dentary evolved from entirely orthal to incorporate horizontal (palinal) motion with the dentary drawn distally (see Crompton \& Hylander 1989; Butler \& Hooker 2005). If distal motion was part of its chewing cycle and M45425 is a lower molariform, the concave sides of its major cusps would be expected to be oriented distally. Finally, based on the morphology of allotherian lower molariforms it is assumed that the row of two high, distinct cusps is the lingual row. Again, it must be stressed that adoption of these assumptions concerning orientation of the crown was driven by the need to describe the morphology of the tooth.

The highest and largest cusp, which is slightly blunted by an apical facet, is assumed to be the mesial cusp of the lingual row. In lateral view the mesial slope of this cusp is slightly convex while the distal is slightly concave. The second lingual cusp is lower and smaller, and its apex is also blunted by wear. In lateral view its mesial slope is almost straight and rises steeply, while its distal slope is distinctly concave and extends distally to form a prominent projection of the crown. These two cusps are blade-like with their assumed mesiodistal length distinctly greater than their width. The buccal row is little more than a serrate ridge and is distinctly lower than the lingual. Shallow notches set off the central cusp from what are essentially mesial and distal ridges. The central basin is

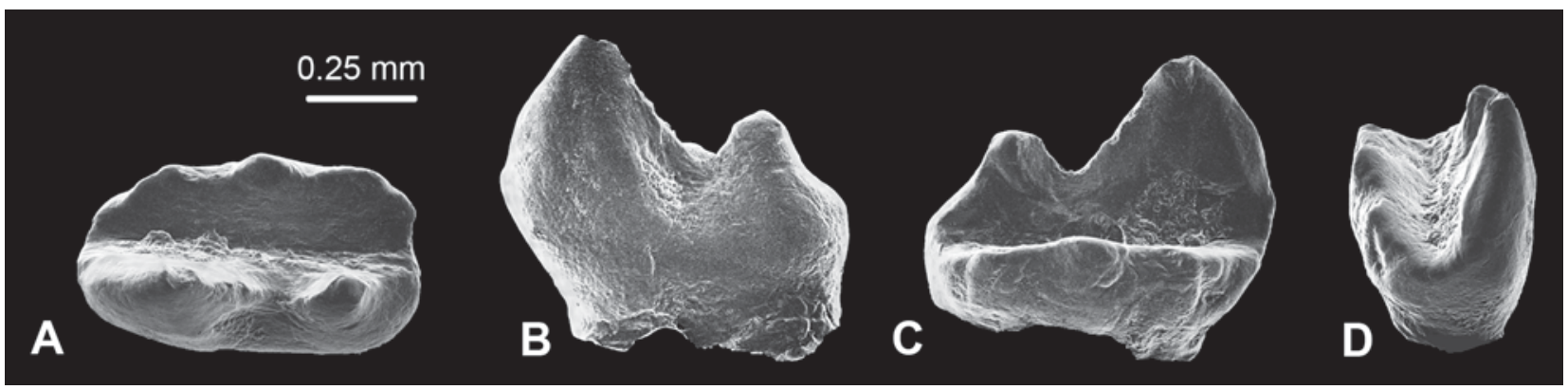

Fig. 6. ?Allotheria, M45425, for purposes of description assumed to be a right, lower molariform (see text for explanation). A - Occlusal view, assumed mesial to left, assumed lingual toward bottom; B - assumed lingual view, assumed mesial to left; $\mathbf{C}$ - oblique view with assumed labial row in foreground, assumed mesial to right; $\mathbf{D}$ - oblique view with assumed mesial end of crown in foreground, assumed lingual to right. 
straight and shows little variation in depth or crosssectional shape throughout most of its length. A very low ridge connects the two rows at the distal end of the crown. Because of its poor state of preservation the extent to which the essential lack of crests connecting the cusp rows and uniformity of the cross-section of the central basin are the products of wear cannot be determined. The configuration of the base of the crown shows that it was supported by a mesodistally elongated root that might have been bifurcated at greater depth. Dimensions of the crown are: length, $0.80 \mathrm{~mm}$; width, $0.45 \mathrm{~mm}$.

Discussion. Crompton \& Hylander (1986) and other workers (see Kemp 2005) have analyzed the evolution of patterns of muscle action and jaw movement in advanced non-mammalian synapsids and early mammals. A distinctive evolutionary theme in some of these lineages is the reconfiguration of the architecture of the skull and jaws reorienting the musculature to produce both the primitive orthal (vertical) and a derived palinal (horizontal, posterior) motion. Among advanced non-mammalian synapsids this functional pattern is reflected in the evolution of the dentitions of diademodontoids (diademodontids and traversodontids) and tritylodontids (Crompton 1972). In diademodontoids varying numbers of cheek teeth became transversely widened and additional cusps formed a series of ridges and basins. For the most part diademodontoids flourished during the Early and Middle Triassic but a few survived into the Late Triassic. One of these Late Triassic survivors was the traversodontid Microscalenodon nanus, which is known from minute isolated teeth found in an Early Rhaetian deposit near Habay-la-Vieille, Belgium (Hahn et al. 1988). Neither Microscalenodon nor other currently known diademodontoids have cheek teeth with crowns consisting of parallel rows of cusps separated by a distinct central basin that closely resemble the crown of M45425.

Comparisons of M45425 were also made with the cheek teeth of tritylodontids, particularly Oligokyphus, which is a member of the Morganucodonsphenodont fauna. The highly derived dentition of tritylodontids consists of upper and lower series of monophyodont cheek teeth separated by diastemata from the incisors (Kühne 1956, Sues 1986). During ontogeny the mesial cheek teeth were lost but the length of cheek tooth battery was maintained or increased by eruption of additional teeth at its distal end. In comparison to many other advanced non-mammalian synapsids (excepting traversodontids) and primitive mammals the cheek teeth of tritylodonts are remarkably uniform in morphology. The cusps are crescentic with the concave side of cusps of the upper cheek teeth facing mesially while on the lowers the concave side faces distally. Three mesiodistally oriented rows of cusps are pre- sent on the upper cheek teeth and two on the lowers. The cusp rows are separated by V-shaped grooves or trenches differing distinctly from the central basins of haramiyid molariforms. Multiple, well-differentiated roots support the crowns of the cheek teeth.

M45425 differs from cheek teeth of tritylodonts in the mesiodistally elongate cusps lacking any indication of crescentic structure and the significant disparity in height between the higher lingual row and the buccal row. Although it might have been accentuated by wear, the central basin of M45425 is broader than the grooves separating cusp rows in tritylodonts. Finally, the simple structure of the root of M45425 is unlike the well-differentiated roots of tritylodontid cheek teeth.

In the recent studies of Late Triassic and Jurassic allotherians ("haramiyidans" and multituberculates) Butler (2000) and Butler \& Hooker (2005) argue that Allotheria is a monophyletic clade. They note that the definitive synapomorphies of the group are derived from the morphology and occlusal pattern of molariform teeth, the only skeletal elements represented in samples of all of the five allotherian subgroups. Crowns of these teeth consist of longitudinal rows of cusps, primitively two in number, separated by a central basin. When occluded the cusp rows of one molariform either fall into the central basin of the opposing molariform or lie lateral to a cusp row. In basal taxa during chewing the mandible was moved orthally; in more derived forms a horizontal (posterior) component was added to the power stroke.

Among the allotherians M45425 most closely resembles haramiyid molariforms, but there are distinct differences. The cusps of haramiyid molariforms tend to have broad, rounded bases and their apices are relatively low unlike the two high, almost blade-like cusps of the assumed lingual row of M45425. The significant disparity in height of the two rows of cusps of M45425 is relatively greater than that found in haramiyids. The central basin of M45425 is a straight groove across the crown while in haramiyids its course is not straight and its base shallows toward the saddle. M45425, with two cusps in the assumed lingual row and three ill-differentiated cusps in the other row, has fewer cusps than in any known haramiyid. Finally M45425 is distinctly smaller than the cheek teeth of any known haramiyid. These differences argue against the hypothesis that M45425 is a cheek tooth of any currently known haramiyid.

Jenkins et al. (1983) described an isolated tooth, MCZ 20879, discovered in the Early Jurassic Kayenta Formation, northeastern Arizona, USA, and suggested that it may be a molariform of a haramiyid. They (Jenkins et al. 1983, p. 221) described the following similarities to Haramiya. "... two rows of cusps, joined at one end by a crest, enclose a central sulcus; one row bears three cusps; the lar- 
gest cusp of the other row is adjacent to the open end of the sulcus, and there are three roots, two of which form a pair below the open end of the sulcus." The following differences from Haramiya were noted, "... the second row bears only two cusps (rather than four or five) and the tooth is smaller $(0.66 \mathrm{~mm}$ long) than European specimens (1 to $3 \mathrm{~mm}$ long)."

Since 1983 the concept of the Haramiyidae has been greatly refined (see Butler \& Hooker 2005 and references cited therein), and, although the similarities remain, the morphology of MCZ 20879 now falls outside the range of variation currently recognized as characterizing members of the Haramiyidae. In the presence of two rows of cusps each formed of two or three blade-like cusps and - with the exception of the more prominent crest closing one of its ends - the straightness and width of the central basin, the MCZ 20879 shows a striking resemblance to M45425. MCZ 20879 differs in its relatively greater breadth $($ length/width ratio $=1.16$ ) and the presence of three roots. If MCZ 20879 and M45425 are respectively representatives of the upper and lower molariforms of the same taxon these differences would be expected. Additionally, given the considerable similarities in composition of the Early Jurassic faunas of the Kayenta Formation and Britain (see Sues 1985), the working hypothesis that MCZ 20879 and M45425 represent the same taxon is viable.

In summary, the possibility that M45425 represents a tritylodontid or other currently known nonmammalian synapsid lineage appears unlikely. The few morphological characters preserved in this isolated tooth favor the working hypothesis that it represents an allotherian lineage (sensu Butler \& Hooker 2005), argue against reference to either the "Haramiyida" and/or Multituberculata. M45425 adds to the documented taxonomic diversity of the Morganucodon-sphenodont fauna. The rapid pace of discovery of new kinds of advanced non-mammalian synapsids and early mammals suggests that full documentation of the diversification of these lineages remains a goal for future research.

\section{Conclusions}

The vertebrate faunas of the Pant 4 and 5 fissures are distinctly more taxonomically diverse than those of the Pant 1 through 3 fissures, which were discovered earlier. This difference was recognized by Gill (2004) who designated the former as the Morganucodon-sphenodont fauna and the latter as the Morganucodon fauna. Although extensively sampled, allotherians in general and haramiyids in particular have not been recognized as members of the Morganucodon fauna. A haramiyid - represented by only six specimens out of probably thou- sands of isolated teeth - is a rare member of the Morganucodon-sphenodont fauna.

The Welsh haramiyid is morphologically similar to Thomasia moorei, which is known from Holwell, Somerset, England; Saint-Nicolas-de-Port, France; and Hallau, Switzerland. They usually are assigned a Late Triassic (Rhaetian or latest Norian) age. These sites are currently thought to be older than those in the fissure fillings of St. Bride's Island, but this difference in age has been called into question by Gill (2004). The dimensions of the molariforms from Pant 4 and 5 are either at the large end of the ranges of variation of molariforms of T. moorei. A second morphological difference is the tendency for greater development of the distolingual basal cingulum of the Welsh molariforms. These differences are not great and given the small size of the available sample the Welsh haramiyid is identified as $T$. cf. moorei. This identification documents extensions of both the geographic and, possibly, stratigraphic ranges of the genus.

The taxonomic affinities of a mammal from Pant 5 fissure represented by a single molariform with a highly derived morphology are enigmatic. Among the currently known Late Triassic and Early Jurassic forms it most closely resembles allotherians but cannot be referred to either the "haramiyidans" or the multituberculates. Provisional identification as an ?allotherian is proposed.

\section{Acknowledgements}

It is a great pleasure to be able to include this study in a volume honoring our colleague Dr. Wolf-Dieter Heinrich who has contributed significantly to our knowledge of the diversity of "haramiyidans" and other members of the mammalian fauna of Tendagaru. Thank you!

My analysis is based on collections made by the late Professor K. A. Kermack and Dr. D. M. Kermack who were assisted in their field and laboratory research by Dr. F. Mussett and P. L. Ferguson of University College London. They also introduced the author to the fissure fillings of southern Wales and southwestern England. Their help and friendship are gratefully acknowledged. Dr. David Pacey recognized the first tooth of a haramiyid discovered in southern Wales. I have benefited from his work as well as collections made after he completed his doctoral research. Dr. J. J. Hooker (The Natural History Museum) and Dr. P. G. Gill (University of Bristol) provided extensive help in organizing and curating these collections. Discussions with them, Prof. P. M. Butler, Prof. S. Evans, M. B. Goodwin played a major role in developing this study and are greatly appreciated. It is a pleasure to acknowledge Drs. Gerhard Hahn, Zofia Kielan-Jaworows$\mathrm{ka}$, and Thomas Martin who provided helpful reviews of an earlier draft of this paper. Dr. Martin Sander's help in providing a German translation of the abstract of this paper is also greatly appreciated. The scanning electron microscope images were obtained with the assistance of Dr. Hooker and the staff of the Electron Microscope Laboratory of The Natural History Museum. Finally it is a pleasure to acknowledge the hospitality extended by Prof. N. MacLeod and Dr. A. Milner during the author's research visits to The Natural History Museum. This is University of California Museum of Paleontology Contribution No. 1930. 


\section{References}

Anantharaman, S., Wilson, G. P., Das Sarma, D. \& Clemens, W. A. 2006. A possible Late Cretaceous "Haramiyidan" from India. - Journal of Vertebrate Paleontology 26: 488-490.

Benton, M. J., Hooker, J. J. \& Cook, E. 2005. British Mesozoic fossil mammal GCR sites. In Benton, M. J., Cook, E. \& Hooker, J. J. (eds). Mesozoic and Tertiary Fossil Mammals and Birds of Great Britain. Geological Conservation Review Series, No. 32: 25-66, Joint Nature Conservation Committee, Peterborough.

Benton, M. J. \& Spencer, P.S. 1995. Fossil Reptiles of Great Britain. 386 pp., Geological Conservation Review Series, No. 10, Chapman \& Hall, London, in association with the Joint Nature Conservation Committee, U.K.

Butler, P. M. 2000. Review of early allotherian mammals. Acta Palaeontologica Polonica 45: 317-342.

Butler, P. M. \& Hooker, J. J. 2005. New teeth of allotherian mammals from the English Bathonian, including the earliest multituberculates. - Acta Palaeontologica Polonica 50: $185-207$.

Butler, P. M. \& MacIntyre, G. T. 1994. Review of British Haramiyidae (?Mammalia, Allotheria), their molar occlusion and relationships. - Philosophical Transactions of the Royal Society of London B 345: 433-458.

Clemens, W. A. 1980. Rhaeto-Liassic mammals from Switzerland and West Germany. - Zitteliana 5: 51-92.

Crompton, A. W. 1972. Postcanine occlusion in cynodonts and tritylodontids. - Bulletin of the British Museum (Natural History), Geology 21: 29-71.

Crompton, A. W. \& Hylander, W. L. 1986. Changes in mandibular function following the acquisition of a dentarysquamosal jaw articulation. In Hotton, N. III, MacLean, P. D., Roth, J. J. \& Roth, E. C. (eds). The ecology and biology of mammal-like reptiles: 263-282, Smithsonian Institution Press, Washington, D. C.

Evans, S. 1980. The skull of a new eosuchian reptile from the Lower Jurassic of South Wales. - Zoological Journal of the Linnean Society 70: 203-264.

- 1981. The postcranial skeleton of the Lower Jurassic eosuchian Gephyrosaurus bridensis. - Zoological Journal of the Linnean Society 73: 81-116.

Evans, S. \& Kermack, K. A. 1994. Assemblages of small tetrapods from the Early Jurassic of Britain. In Fraser, N. C. \& Sues, H.-D. (eds). In the shadow of the dinosaurs Early Mesozoic Tetrapods: 271-283, Cambridge University Press, Cambridge.

Gill, P. G. 2004. Kuehneotherium from the Mesozoic fissure fillings of South Wales. 165 pp., unpublished PhD Thesis, University of Bristol.

Hahn, G. 1973. Neue Zähne von Haramiyiden aus der Deutschen Ober-Trias und ihre Beziehungen zu den Multituberculaten. - Palaeontographica, Abt. A 142: 1-15.

Hahn, G., Lepage, J.-C. \& Wouters, G. 1988. Traversodontiden-Zähne (Cynodontia) aus der Ober-Trias von Gaume (Süd-Belgien). - Bulletin de l'Institut Royal des Sciences Naturelles de Belgique: Sciences de la Terre 58: $177-186$.

Hahn, G., Sigogneau-Russell, D. \& Wouters, G. 1989. New data on Theroteinidae: their relations with Paulchoffatiidae and Haramiyidae. - Geologica et Palaeontologica 23: 205-215.

Heinrich, W.-D. 1999. First haramiyid (Mammalia, Allotheria) from the Mesozoic of Gondwana. - Mitteilungen aus dem Museum für Naturkunde in Berlin, Geowissenschaftliche Reihe 2: 159-170.

- 2001. New records of Staffia aenigmatica (Mammalia, Allotheria, Haramiyida) from the Upper Jurassic of Tendaguru in southeastern Tanzania, East Africa. - Mitteilungen aus dem Museum für Naturkunde in Berlin, Geowissenschaftliche Reihe 4: 239-255.
- 2004. Allostaffia, a new genus name for Staffia Heinrich, 1999 (Allotheria, Haramiyida) preoccupied by Staffia Schubert, 1911 (Protista, Foraminifera). - Mitteilungen aus dem Museum für Naturkunde in Berlin, Geowissenschaftliche Reihe 7: 153.

Jenkins, F. A. Jr., Crompton, A. W. \& Downs, W. R. 1983. Mesozoic mammals from Arizona: New evidence on mammalian evolution. - Science 222: 1233-1235.

Kemp, T. S. 2005. The origin and evolution of mammals. 331 pp., Oxford University Press, Oxford.

Kermack, D. M., Kermack, K. A. \& Mussett, F. 1968. The Welsh pantothere Kuehneotherium praecursoris. - Journal of the Linnean Society of London (Zoology) 47: 407-423.

Kermack, K. A., Mussett, F. \& Rigney, H. W. 1973. The lower jaw of Morganucodon. - Zoological Journal of the Linnean Society 53: 87-175.

- 1981. The skull of Morganucodon. - Zoological Journal of the Linnean Society 71: $1-158$.

Kielan-Jaworowska, Z., Cifelli, R. L. \& Luo, Z.-X. 2004. Mammals from the age of dinosaurs: origin, evolution, and structure. 630 pp., Columbia University Press, New York.

Kühne, W. G. 1949. On a triconodont tooth of a new pattern from a fissure-filling in South Glamorgan. - Proceedings of the Zoological Society of London 119: 345-350.

- 1956. The Liassic therapsid Oligokyphus. $x+149$ pp., Trustees of the British Museum, London.

Luo, Z.-X. 1994. Sister-group relationships of mammals and transformations of diagnostic mammalian characters. In Frazer, N. C. \& Sues, H.-D. (eds). In the Shadow of the Dinosaurs - Early Mesozoic Tetrapods: 98-128, Cambridge University Press, Cambridge.

Marsh, O. C. 1880. Notice on Jurassic mammals representing two new orders. - American Journal of Science, Ser. 3, 20: $235-239$.

Owen, R. 1871. Monograph of the fossil Mammalia of the Mesozoic formations. - Monographs of the Palaeontological Society 33: $1-115$.

Pacey, D. 1978. On a tetrapod assemblage from a Mesozoic fissure fill, South Wales. 273 pp., unpublished $\mathrm{PhD}$ Thesis, University College of London.

Parrington, F. R. 1947. On a collection of Rhaetic mammalian teeth. - Proceedings Zoological Society, London 116: $707-728$.

Poche, F. 1908. Einige notwendige Änderungen in der mammalogischen Nomenclatur. - Zoologische Annalen 2: 269-272.

Robinson, P. L. 1957. The Mesozoic fissures of the Bristol Channel area and their vertebrate faunas. - Journal of the Linnean Society (Zoology) 43: 260-282.

Rowe, T. B. \& Gauthier, J. A. 1992. Ancestry, paleontology, and definition of the name Mammalia. - Systematic Biology 41: 372-378.

Säilä, L. K. 2005a. A new species of the sphenodontian reptile Clevosaurus from the Lower Jurassic of South Wales. Palaeontology 48: 817-831.

- 2005b. A new species of the sphenodontian reptile Clevosaurus from the Lower Jurassic of South Wales and tetrapod diversity of St Bride's Island. - Journal of Vertebrate Paleontology 25 (Supplement to 3): 108A.

Sigogneau-Russell, D. 1989. Haramiyidae (Mammalia, Allotheria) en provenance du Trias superieur de Lorraine (France). - Palaeontographica Abt. A 206: 137-189.

Simpson, G. G. 1947. Haramiya, new name, replacing Microcleptes Simpson, 1928. - Journal of Paleontology 21: 247.

Sues, H.-D. 1985. First record of the tritylodontid Oligokyphus (Synapsida) from the Lower Triassic of Western North America. - Journal of Vertebrate Paleontology 5: 328-335.

- 1986. The Skull and Dentition of Two Tritylodontid Synapsids from the Lower Jurassic of Western North America. - Bulletin of the Museum of Comparative Zoology 151: 217-268. 